\title{
Accounting for the right to assign a task in meeting interaction
}

Jan Svennevig and Olga Djordjilovic

University of Oslo, Dept. of Linguistics and Scandinavian Studies

Abstract

This article analyzes how meeting participants account for their right to assign a work-related task to a colleague in meeting interaction. It focuses on accounts which appeal to benefactive effect, that is, the benefits of the proposed action to the operation of the organization. Such accounts are often formulated as general strategies or policies for action. They are shown to be related to the deontic rights of the participants in that subordinates engage in more extensive accounting practices than do managers. Accounts that evoke other interests than benefits to the organization are shown to be vulnerable to being questioned or rejected. The study thus contributes to understanding of how benefactive stance is used for legitimizing requests for institutionally relevant actions.

Keywords: meeting interaction, task assignment, accounts, requests, deontic rights, benefactive stance, strategy

1. Introduction

Assigning work tasks is commonplace in the day-to-day operation of organizations and in workplace meetings. One of the main purposes of meetings is to decide who should do what. The job descriptions of certain institutional positions such as managers include the right to assign tasks to subordinates. Thus, persons occupying certain institutional roles have a deontic status (Stevanovic \& Peräkylä, 2014) that can be used as a resource in interaction, providing for the legitimacy of requesting 
certain services from their co-workers. In such cases, task assigning is not followed by an account. However, work tasks can vary both in complexity and novelty. Certain tasks are a part of the work routine and meeting participants can treat them as clearly pertaining to a specific participant due to her area of responsibility. Mangers often assign such tasks just by formulating a decision. Another option is that a participant assigns such a task to herself. In both cases participants treat the core action as unproblematic and not requiring a discussion or an explanation. Other tasks may not be treated as a grounded in pre-defined rights and obligations inherent in the speaker's institutional role. For instance, employees sometimes make requests to their peers or to their manager, or managers assign tasks that are new, complex or for some reason treated as difficult to perform. In such cases, participants commonly give accounts for making the request. In this article, we describe the forms such accounts may take and what sorts of reasons or motivations are invoked in them. Furthermore, we analyze how accounts may be challenged and negotiated in cases of disagreement about the legitimacy of a specific request.

Before proceeding to the analysis, we will present some previous studies of requests and task assignment, and we give some theoretical background on accounts and deontics.

\section{Task assignment in meeting interaction}

The setting under investigation here is management and team meetings in various companies (cf. below). Previous studies of meeting interaction have to a large extent focused on such things as turn-taking patterns and topic management (Svennevig, 2012a). This study instead focusses on a central and typical activity enacted in such settings, namely negotiating the responsibility for carrying out workplace tasks. Task assignment may be considered a type of directive action that is rather specialized to organizational contexts. They are most often realized as requests, but may also 
involve other actions as well, such as offers in cases where speakers assign tasks to themselves (cf. example 5 below).

Directives have been studied in workplace interaction by several researchers. Using a speech act approach, Vine (2004) gives an extensive overview of forms of directives in a corpus of meetings and other workplace encounters. Not much has been written about task assignment specifically, but Svennevig (2011) describes how managers may assign tasks to subordinates using different interactional styles, taking a more collaborative or a more authoritative stance vis-à-vis the interlocutor.

Concerning epistemics, they may either claim superior knowledge in diagnosing the situation and prescribing a solution, or instead invite opinions from the subordinates and contribute to a more dialogical establishment of solutions. Concerning deontics, they are observed to choose request formats that vary in the degree of imposition, presenting the task as either a common or an individual responsibility.

Djordjilovic (2012a) also gives relevant background for the current study in that she analyzes how concrete, 'practical' requests for action are grounded in general, 'strategic' claims of necessity and desirability. Evoking strategic claims is shown to be an especially useful resource for subordinates that do not in principle have deontic rights to decide on the future actions of their managers. A typical example of such a claim is "we have to be proactive". These statements incorporate condensed aspects of organizational logic and values which are presented as generally known and accepted.

In a different type of setting, Rossi (2012) found that linguistic realizations of requests varied according to whether the requested action was part of a more encompassing common project or not. We take this as a point of departure for investigating whether the common organizational 'project' of the employees is consequential for how requests are accounted for. A characteristic feature of interaction between colleagues in an organization is that they can be considered as involved in an overarching 'joint project', namely the operation of the organization. Interacting in the capacity of fellow employees, they may be expected to share a 
commitment to the goals of the organization and orient to them as the ultimate legitimation of their professional activities.

\section{Theoretical background}

In this paper we base our identification of accounts on Antaki's understanding of them as a window into "the social reasoning that people go through to make sense of their words and (perhaps) impose that sense on other people" (1994: 1). Accounts are recognized not by their form, but by the interactional function they have in reference to the surrounding sequential context. Accounts address some puzzle, rather than just provide information. Flowingly, we can say that accounts retard progressivity of the core activity. In our examples, this core activity is assigning work tasks. Antaki presents three main types of accounts: those that propose a causal relation, accounts that "make plain", and warranting accounts (1994: 4). In this paper we deal with the last type of accounts, those that warrant task assignment by presenting the logic behind it and thus address the legitimacy of the proposed action and /or the legitimacy of assigning it to a particular meeting participant.

Clayman and Heritage (2014) show how in mundane conversation requests may be accounted for by expressing the beneficial effects of the action for the speaker. This may be relevant in an organizational context as well, as we will show in our analysis. But in addition, we consider another type of beneficiary that occurs prominently in our data, namely the organization. Through our examples, we will investigate how the operation of the organization is invoked as a type of overarching project and an important basis for legitimizing requests.

In our analysis we refer to concepts of deontic stance and status (Stevanovic 2011, Stevanovic and Peräkylä 2014). As described in the introduction to the special issue (Stevanovic \& Svennevig, this issue), deontic stance refers to interactional displays of authority in certain domains of action relative to a co-participant. Deontic status, by contrast, refers to the relative position of authority that a participant has 
vis-à-vis others by reference to external features, such as personal history or position in societal and institutional structures. In our case, the participants' relative positions in the organizational hierarchy are especially relevant to consider in analyzing how their entitlement to assign tasks is displayed and accounted for in the talk.

\section{Data and method}

The data for the present study comes from two corpora of video-recorded business meetings in various corporations. The first is a collection of 5 management meetings in a Norwegian holding company owning various broadcasting infrastructure and distribution companies across Scandinavia. At the time of the data collection, the company was undergoing a major restructuring process. The language used in these meetings in Norwegian, and all the participants are native speakers.

The second is a collection of 17 management and team meetings in two companies, one in the production sector and the other in the finance sector. They are both merged from originally Swedish and Finnish companies, and the participants are mainly from these two countries. The working language is English, which they all speak as a foreign language with varying degrees of proficiency. ${ }^{1}$

Using a conversation analytic approach, we have identified sequences where tasks are assigned to employees, and focussed on the ones where requests are backed by accounts. The analysis is based on the theoretical framework of social epistemics and deontics, as described in the introduction to the special issue (Stevanovic \& Svennevig, this volume).

Accounts are found in a large number of task assignments in our data. However, as noted above, the need to account for a request may be expected to be more pressing when the entitlement to make it is not grounded in the speaker's institutional status. The analysis will start by an example of a manager assigning a

\footnotetext{
${ }^{1}$ The corpus was collected by Helena Kangasharju in connection with a project at the Helsinki School of Economics on working language in newly merged companies (for more details, see Kangasharju, 2007). We are grateful to Helena for giving us access to the corpus.
} 
task to one of his subordinates. We will then consider an example of the opposite relationship, with a group of employees asking their manager to take on an assignment, yielding stronger accounting practices. However, the strongest evidence for underlying norms of conduct is often found in deviant cases, in which the norms are brought to the surface by being breached or commented upon (Heritage 1984). Therefore, we conclude the analysis by investigating two instances where the legitimacy of a task assignment is questioned or challenged and subsequently explicitly brought up for discussion.

\section{Task assignment by the manager}

We will start by analyzing an instance where a manager assigns a task to one of his subordinates. The excerpt comes from a management meeting in the human resource department of the Swedish-Finnish production company. The meeting is led by the (Swedish) HR director, Peter $(P)$, and the eight other participants are HR managers with different areas of responsibility. The excerpt starts as Peter introduces a new agenda point on what he sees as an unfavorable practice of salary determination in Finland, namely giving managers a flat, general rise instead of basing salary increases on individual performance. In the extracts we analyze here (1 and 2), he asks two of the Finnish participants to prepare a memo on how this practice can be changed. The two are Mikko, who is in charge of salaries, and Arto (A), who is in charge of the London office.

(1) Salaries

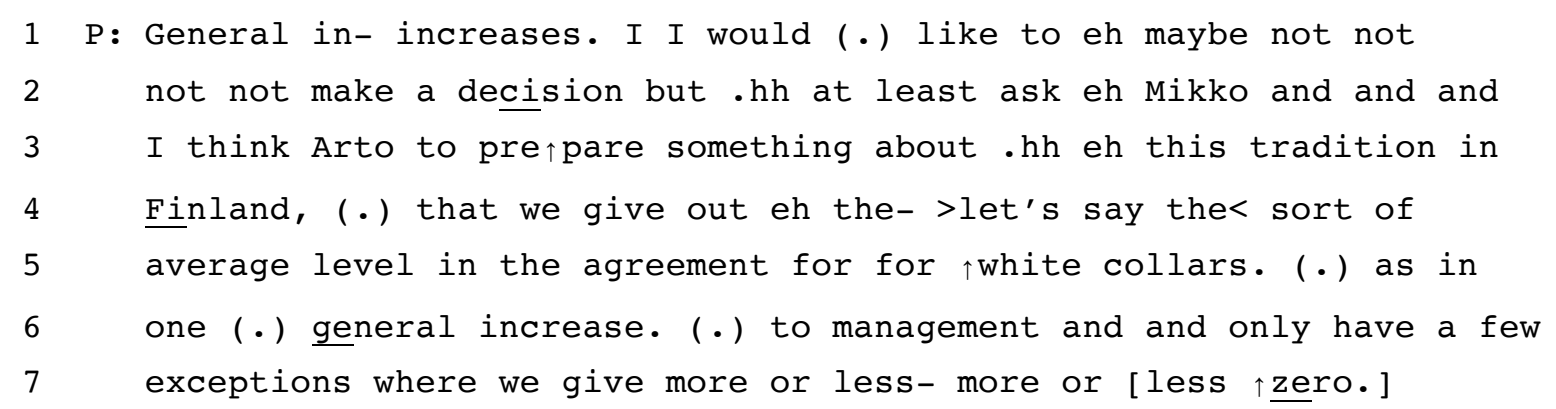




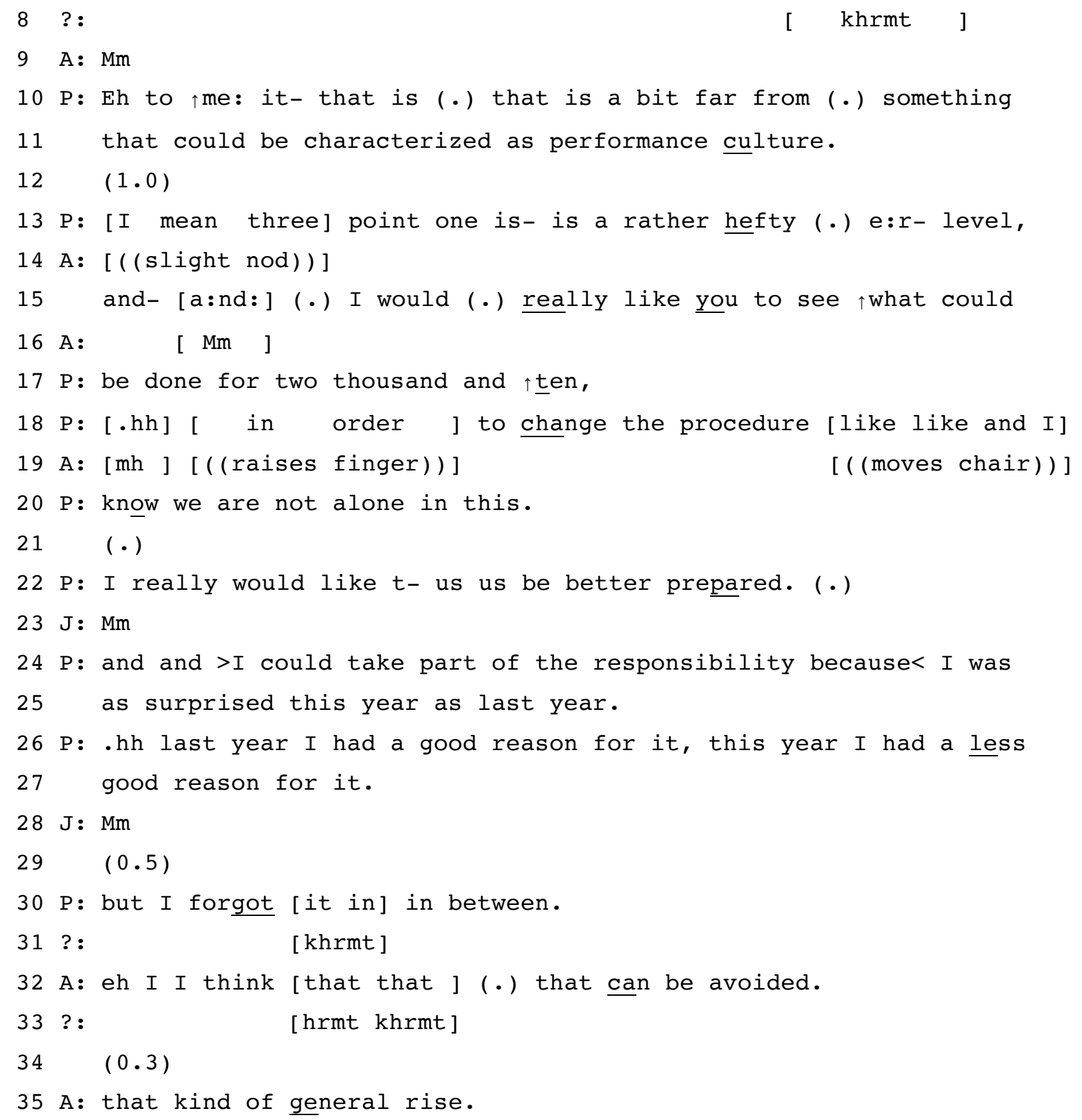

The manager introduces the topic by signalling his intention to ask the two Finnish representatives to "prepare something" (later specified as "a short PM", see below). This action may be characterized as a pre-request in that it has a metacommunicative formulation ("I would like to [...] ask") and thus projects a request rather than performing one in itself. Furthermore it occurs as a topic initiation, where announcing a topic for discussion is the expected action rather than a concrete request for action (Svennevig, 2012b). The formulation of the (pre-)request itself is in terms of what the manager 'would like' them to do, thus realizing a rather weak deontic stance, expressing the (subjective) desirability, rather than the (objective) 
necessity, of the proposed action. The deontic force is somewhat upgraded by the adverb 'really' in the repeated versions in lines 15-17 and 22. His entitlement to assign the task to them is displayed by the fact that he does not show any consideration for the possible contingencies relating to their ability or willingness to comply with the request. ${ }^{2}$

Having thus signalled a forthcoming task assignment, Peter now gives several accounts for the need to take action. First, he points to the negative effects of the current practice, namely that it doesn't contribute to performance culture (line 10-11). The account is not formulated as a 'strategic claim' (such as 'we need to develop performance culture', cf. Djordjilovic 2012a) but the term 'performance culture' itself has deontic implications in that it refers to something (in this context) unequivocally desirable. It may be considered an inference-rich category (Sacks, 1992), evoking an organizational logic where enhancing employee performance is an acknowledged goal. Furthermore, he gives another account that evokes another negative consequence of the current practice for the organization, namely that the raises are costly ("hefty level", line 13). Also the expressed wish that they should be "better prepared" (line 22) may be considered an account, grounding the request in the interests of the of the HR department. Common to all these accounts is thus that they present the organization as the beneficiary of the proposed action, obtaining more high-performing employees, saving money and improving administrative procedures.

Peter produces the account in line 10-11 in a rather non-assertive manner, presenting the reasons as his personal opinion ("to me..."), downgrading the potential criticism involved ("a bit") and using an epistemic hedge "'what could be characterized as"). Thus, in addition to the weak deontic stance displayed in the prerequest, he also takes a weak epistemic stance in accounting for it. Thus, the entitlement to assign the task is not grounded in displays of deontic and epistemic authority.

\footnotetext{
2 Yet, in his turn increment (lines 24-30), he makes a concession of own responsibility for the current situation, thus pre-empting objections and mitigating the potential criticism inherent in the request.
} 
Neither of the addressed recipients respond explicitly to the (pre-)request. Arto aligns as addressee of the turn by producing continuers (line 9 and 16) and makes a bid for the floor by raising his finger in line 16 (Ford, 2008). When he subsequently takes the floor, he responds by agreeing with Peter's point of view on the issue under discussion (line 32-35). By doing this, he goes into the discussion of what can be done about the situation, and thus implicitly accepts the requirement that this practice should be dealt with and that he is (at least partly) responsible for contributing to solving it.

In sum, we see that Peter takes a rather weak deontic and epistemic stance in the formulation of the pre-request and the account. The necessity of taking action is thus not grounded in displays of personal or institutional authority, but in a series of accounts referencing the beneficial effect for the organization. His subordinates seem to orient to his entitlement to assign such a task in that they do not even produce an acceptance token, but instead respond in a way that takes compliance for granted. We may thus see this as an orientation to the manager's deontic status (his institutional authority) rather than his deontic stance (his far from authoritatively formulated request).

After some more discussion among the participants about how this practice could be altered and the time schedule for dealing with it, Peter concludes the topic by a formulation of upshot, summing up what needs to be done and who is responsible for it (cf. Barnes, 2007):

(2) Salaries (ctd.)

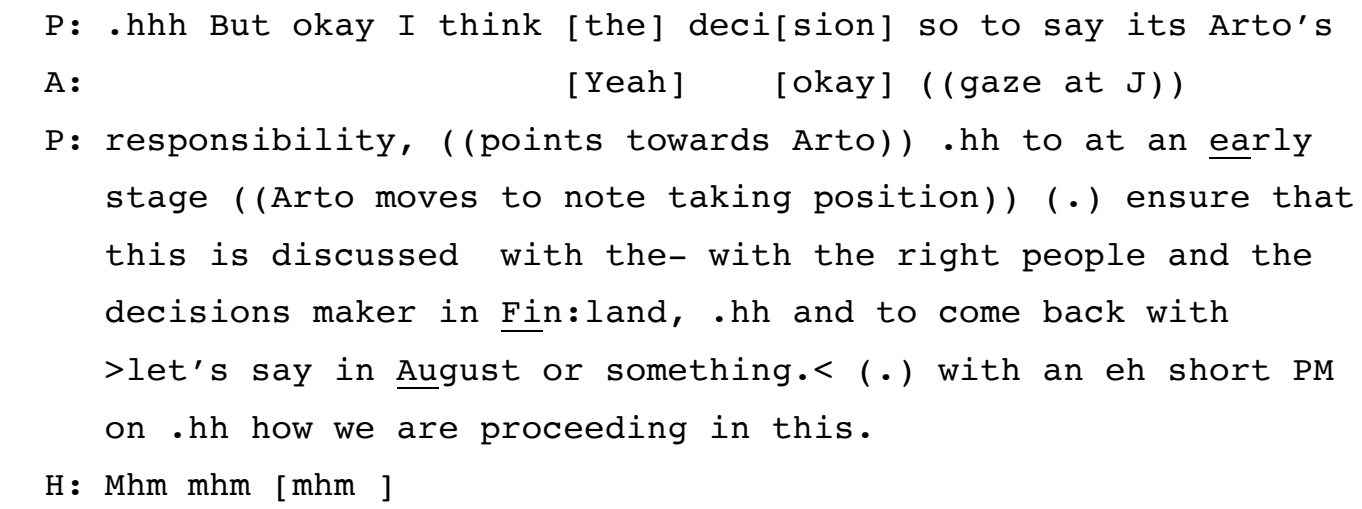


Without Arto ever having expressed a positive or negative response to the request, Peter announces "the decision" about his responsibility to carry out the assigned task. He adds an increment (line 10) opening the possibility that the memo may also include objections against his expressed point of view on the issue under discussion, thus continuing to take a weak epistemic stance. However, his deontic stance is now significantly upgraded. What was initially presented in weak deontic terms as something he "would like" is now reformulated as an institutionally grounded "decision". Here, the manager more explicitly bases his entitlement on the organizational realities, such as institutional procedures (decisions) and structures (areas of responsibility). Here again, he does not invite any response from Arto, and Arto does not volunteer one either. His only response is a shift in posture from leaning back in his chair to sitting up with his right hand on his papers, assuming what could be called a 'note-taking position' (line 4). This posture displays readiness to act, and thereby compliance with the assignment. The manager's right to assign the task as a unilateral announcement thus seems to be taken for granted by both parties and not in need of any expression of commitment in the form of a verbal response.

In these two excerpts we see an example of a manager assigning a task to his subordinates. There is not extensive accounting, but he invokes the benefits for the organization as the main motivation for the request. He does not take a strong deontic stance, but his (pre-)request is treated as authoritative by the addressee in that he presupposes (rather than asserts) compliance in his response, thus acknowledging the authority of his deontic status as the department manager. As noted by Stevanovic \& Peräkylä (2014: 191), "while deontic stance and deontic status are usually congruent with each other, this is not always the case: indeed, highly authoritative speakers rarely need to command [...]." 
In order to see how this contrasts with a request that is not similarly grounded in institutional authority, we will now turn to an extended sequence in which a subordinate makes a request to the manager. As we will see, this situation calls for a more explicit and extensive accounting for the request.

6 Asking the manager to act

The next example is taken from a management meeting in the IT section of the Norwegian telecom company. The manager, Tor, has presented a strategic document, a new governance model for the organization. He has opened the discussion with a claim that the best way to proceed is to initiate a dialogue with the daughter companies and find out together with them the best practical solutions for the implementation of the new model. At this point, Lars proposes a modification of this strategy, followed by a more concrete proposal:

(3) Communication plan

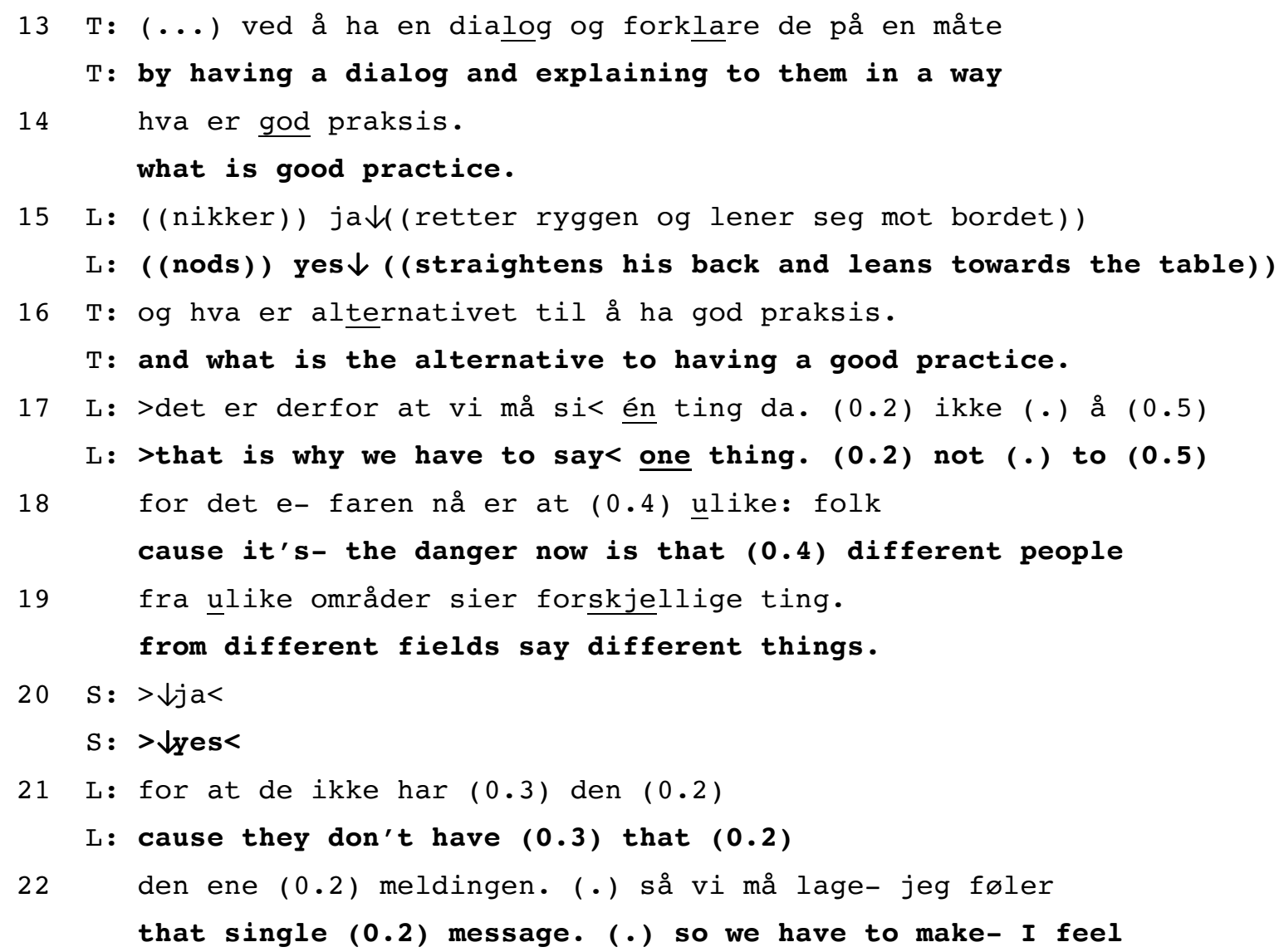


In line 17, Lars makes a general, 'strategic' claim of necessity ("we have to say one thing"), in which he takes a strong deontic stance with high entitlement to define a general principle for the groups' actions. We will refer to such formulations as 'policy statements'. Lars initiates the turn by presenting it as a logical consequence of what the manager has just said ("that is why..."), thereby 'deriving' the legitimacy of his own claim from the previous turn. In line 18 Lars continues his turn by providing an account for the proposed strategy. The account spells out the negative consequences (for the company) if the strategy is not implemented - people from different departments will provide different information to the daughter companies. The company is thus presented as the beneficiary of the proposed action, with a focus on preventing negative effects.

Having made a policy statement and given an account for it, Lars starts claiming the necessity of a more concrete course of action. He initiates a sentence that projects a proposal with a strong deontic stance: "we have to make-" (line 22), but then aborts this turn beginning and redesigns the turn as a statement of need: "I feel we need...”. In doing so, he downgrades his deontic stance, both by reducing the expression of obligation and also by presenting it as merely a personal opinion (or 'feeling'). Just previously, Lars had used the format 'we have to' to formulate a general strategy. But the action he is proposing this time is not a general or abstract one but a rather concrete task (formulating a communication plan). Thus, his initial formulation would potentially be heard as making a request for a concrete course of action by the others, a task assignment. A statement of need is a weaker expression of directive intent, stating that a precondition for proposing a future action is met rather than requesting one (thus it can be better characterized as a pre-proposal or a pre-request). Thus, his self-repair shows an orientation to the limitations of his deontic status in making requests to the group. 
In this excerpt we see that a subordinate may take a strong deontic stance in formulating strategy and, once the strategy is accepted, use it as grounds for proposing a more concrete line of action. The policy statement presents the organization as the beneficiary of the proposed line of action and thereby both accounts for the proposal and upgrades the speaker's entitlement to make it.

At this point, Lars has indicated the need for some future action in order to ensure a uniform message to the different daughter companies. However, he has not specified what ought to be done more concretely or who should be responsible for taking action. In the next excerpt, recorded 27 minutes later in the same meeting, Lars returns to the issue with a more concrete request. In the meantime, the meeting participants have been discussing when and how to present the new strategy to the relevant employees in the daughter companies. During a short break, when Tor exits the meeting room to take a phone call, the subordinates agree that they would like him to be present at a conference with the daughter companies and explain the strategy to them in public. Upon his return to the meeting, Tor announces that he will have to leave soon and then he moves on to formulate the gist of the whole previous discussion (line 250). At that point Lars takes the floor and makes a concrete request for action from Tor:

\section{(4) Presentation}

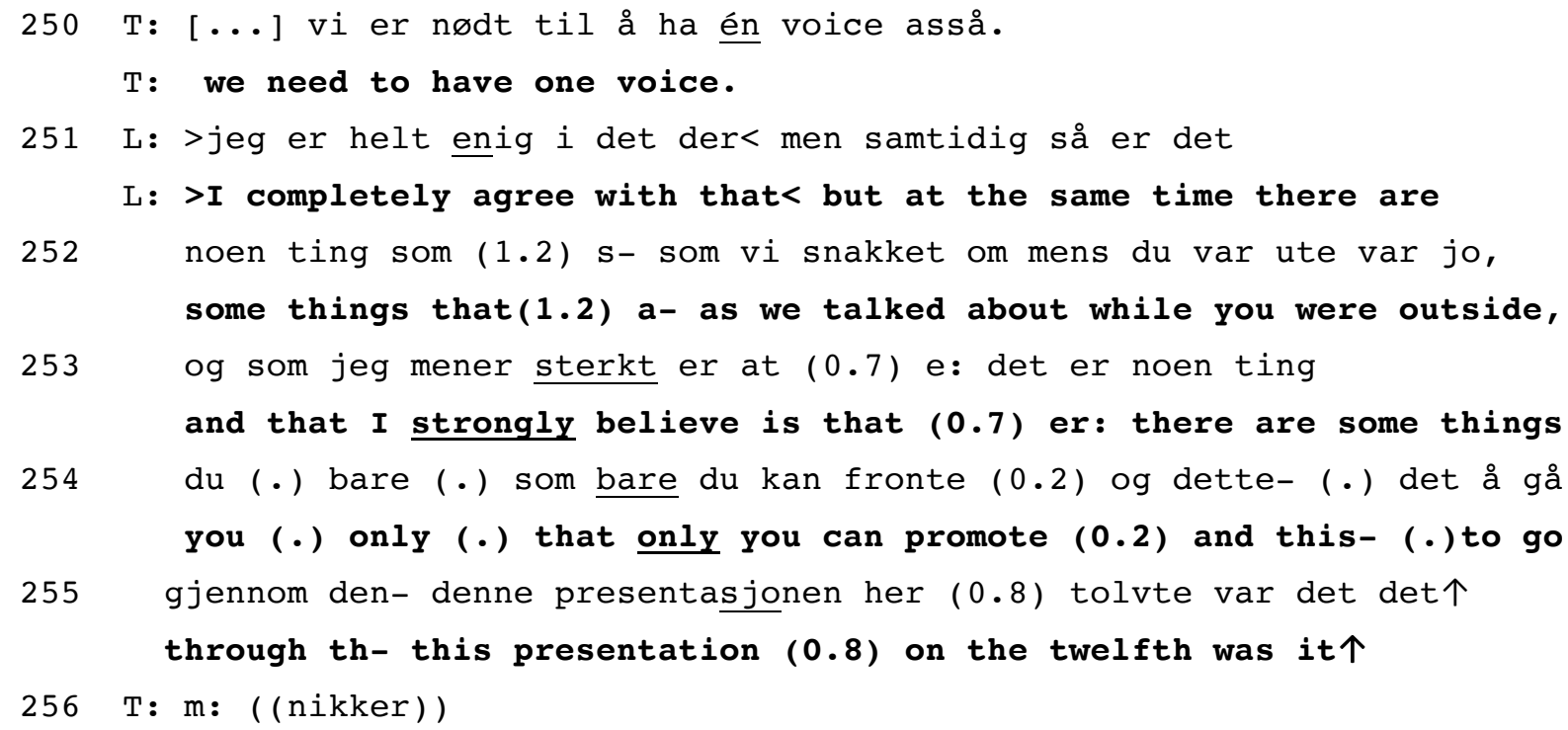




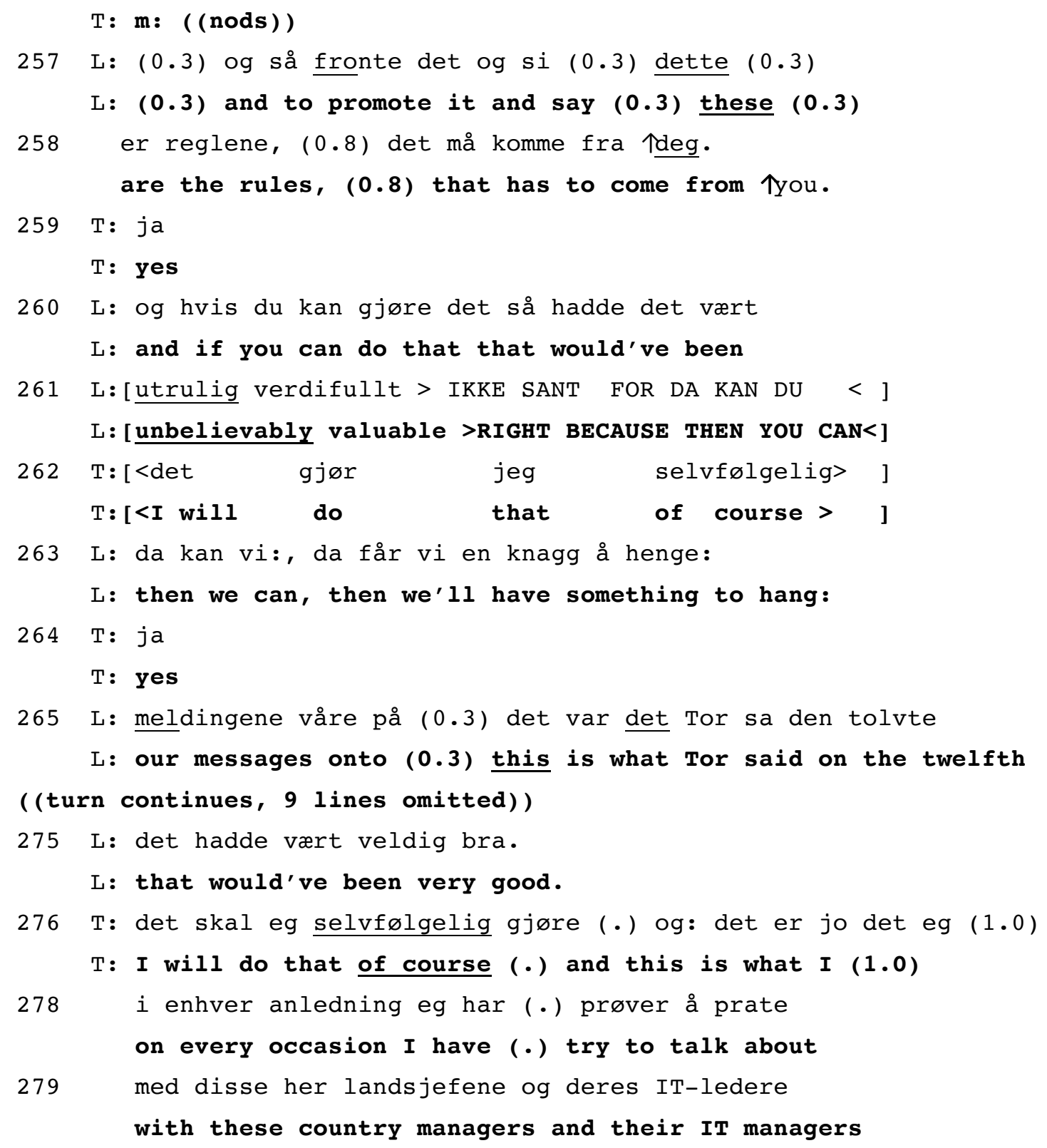

Tor's formulation of gist in line 250 is another example of a policy formulation which claims necessity of a general line of action and assigns it to an unspecified collective, 'we'. In his response, Lars constructs an elaborate turn that eventually leads to a concrete request. The request is preceded by a range of prefaces - accounts which preemptively address issues of entitlement, contingency and benefactivity. In the following we will analyze this extended account.

In line 251 Lars responds to Tor by offering an explicit agreement, and then turns it into a (partial) disagreement (cf. Sacks 1987). He thus endorses Tor's strategic claim, but then initiates a challenge at the level of concrete action (the 
'tactical level'). First, he produces an account which explicates his entitlement to produce the upcoming request. The entitlement is based on a) an agreement with the other team members ("as we talked about while you were outside", line 252), thus turning Lars into a spokesman of the group as a whole, and b) on his own personal conviction ("I strongly believe", line 253). In the next step, Lars produces a claim grounded in the organizational logic about Tor's privileged status and authority ("there are some things that only you can promote", lines 253-254). In other words, he makes explicit reference to a shared epistemic territory, 'the way things work around here' (cf. Heritage 2012). Then in the following step, Lars can use this description as an account for a deontic claim, "that has to come from you". Even though the claim nominates Tor as the responsible agent, it is not a straightforward request, but a pre-request that invites an offer. Lars here takes a strong deontic stance, claiming absolute necessity of Tor's action, but the legitimacy of the claim is grounded in purportedly shared knowledge about organizational realities, such as areas of responsibility and institutional authority.

Tor responds with minimal acknowledgement, and nothing more. By passing the opportunity to make an offer he ignores or resists the directive implication in Lars's statement. Lars then pursues compliance by making an explicit request for action (line 260-261). This time he uses a request format associated with weak entitlement, namely a hypothetical construction ("if you could") which makes the request highly contingent upon Tor's acceptance. The request is combined with a high-grade token of appreciation ("it would've been unbelievably valuable") which expresses the desirability, rather than necessity, of the requested action. In short, Lars takes a weak deontic stance, displaying significant limitations in his entitlement to assign this task to Tor. Instead, he proceeds to account for the request by spelling out the benefits for the operation of the company (lines 263-265).

In line 262 Tor offers an unambiguous acceptance and commits himself to future action. The early recognitional onset, leading to overlap with the final part of the request, is hearable as upgrading of the affiliative character of the response, thus 
compensating for the possible resistance implied by his previous minimal response in line 259. Tor finishes his turn with "of course", which treats the expression of high contingency in Lars' request as unnecessary (cf. Stivers, 2011). However, Lars orients to a need to account for the request even after that request has been so strongly accepted. Instead of accepting the offer, Lars treats Tor's response as an interruption and resists relinquishing the floor to him. Instead of ending his turn at the first transition relevance place (after the word 'valuable'), he latches on a tag and a turn increment with increased tempo and volume (line 261), thus performing a rushthrough and sequentially deleting Tors turn. Lars' increment provides a more detailed account of the benefits from the requested action for Lars and his colleagues in the group. By not just accepting Tor's compliance, Lars may be seen as orienting to his low entitlement to perform the request. It is important for him to present additional reasons motivating and legitimizing the request. But perhaps more importantly, underlining the beneficial effects of the projected action for the organization upgrades the deontic force of the request. In this context, where Tor has announced that he has to leave the meeting, this may be considered a pursuit of an even stronger display of commitment from Tor.

Tor indeed responds, once again, with a strong expression of commitment, upgraded by 'of course', signaling that for him, this is an obvious thing to do (line 276). Furthermore, he adds an account which treats the requested action as just another instance of what he normally does all the time. In this way, he conveys that his commitment to come to the conference is by no means a change in attitude, or a mere compliance with the wish of the subordinates, but a natural continuation of an activity that he has practiced all along. In this way, Tor contests the need for extensive accounting for the request, and implicitly, the need to lay down the benefits for the organization, as he already is aware of them.

In this example we have seen how a subordinate uses elaborate accounts in order to provide for the legitimacy of assigning a task to his manager. One of the resources he uses is reference to the requirements of the organizational procedures, 
thus grounding the necessity of requested action in their common epistemic field. Another resource is upgrading his entitlement by presenting the request as based on a collective wish of the whole group rather than just a personal one. Finally, and most importantly, he motivates the request by stressing the benefits to the successful operation of the company. In this way, the accounts invoke the participants' shared commitment to a 'joint project' and motivate the request by presenting the organization as the beneficiary of the proposed action.

\section{Contested accounts}

In the next two extracts, we will see that accounts are sometimes contested, leading to explicit discussions about what counts as a legitimate reason for assigning a task to someone. The examples are from a meeting in the editorial board of a corporate magazine. In the first example, the members are talking about their efforts to try to hire translators from a large daily newspaper, and one of the journalists, Liisa (L), has reported that she has made an enquiry to someone there, but that she is "not very optimistic". At that point, the editor, Clas (C), makes a suggestion to contact the editor in chief instead, and subsequently offers to do it himself (line 8). Liisa accepts his offer, but gives an account for this wish (line 11-12) which is then challenged by Clas (line 15-17). Two other journalists also join the discussion, Mats (M) and Vesa (V).

(5) Editor in chief

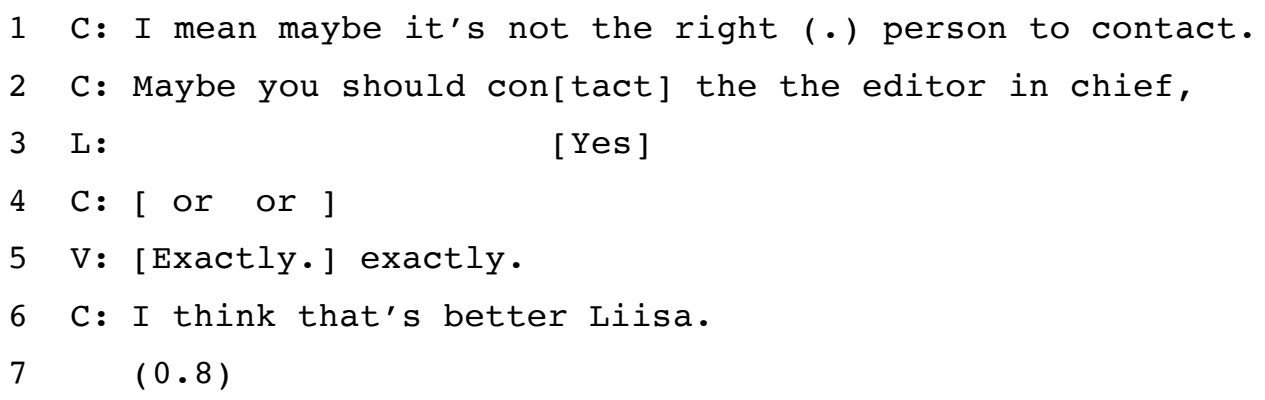




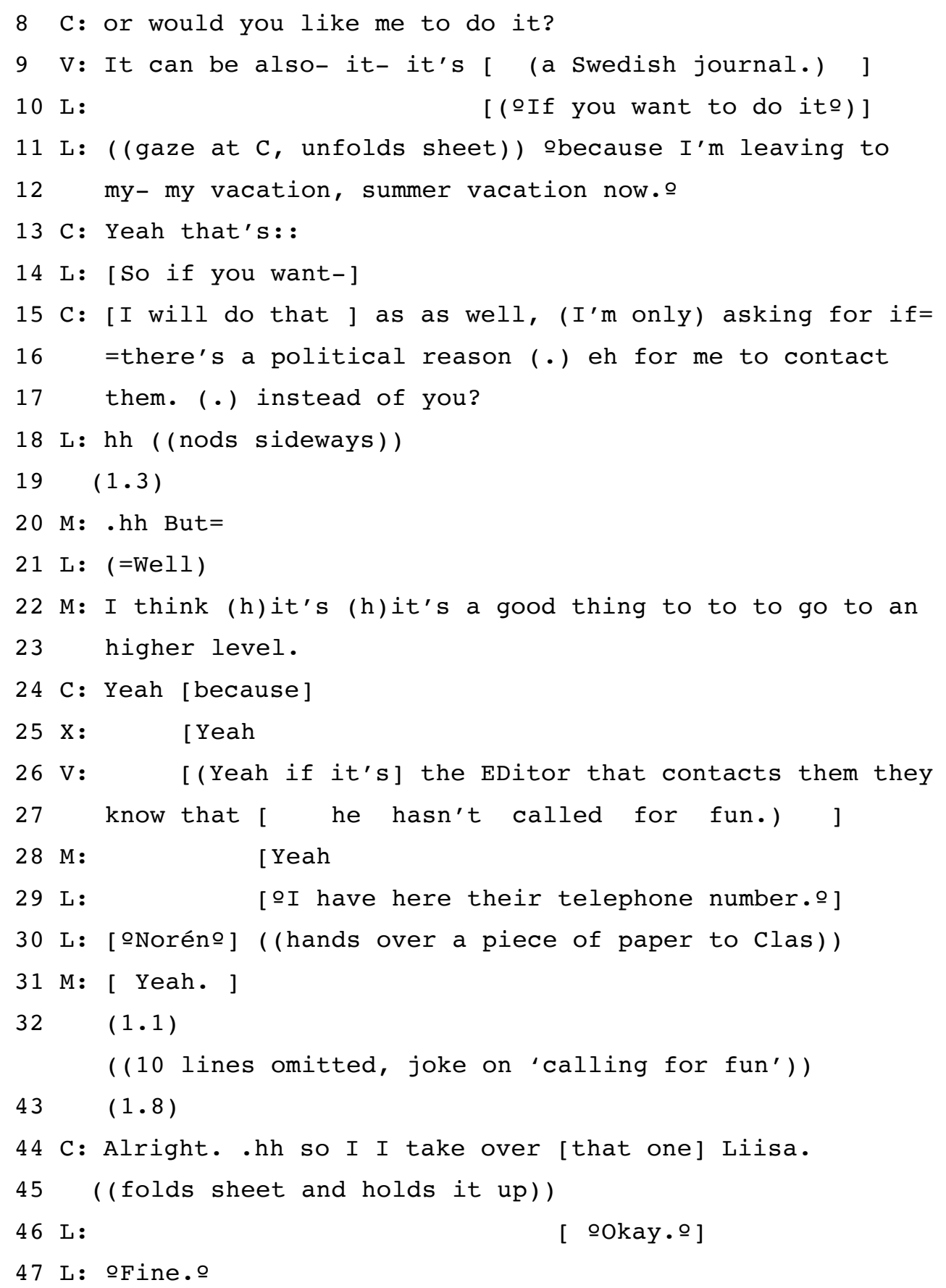

Clas' question in line 8 is framed as what is desirable to Liisa, what she "would like", thus turning it into an offer. Liisa takes a rather weak deontic stance in her response in line 10-12. First, she does not answer by a token of acceptance, which would be the type-confirming response. Instead, her response takes the form of a conditional clause ("if you want to do it"), which is not completed, but which conventionally projects an expression of desirability (something like 'it would be good'). She thus presents acceptance as contingent on what he wants, thus downplaying the 
importance of her own wants. Second, she gives an account by invoking a contingency that purportedly hinders her from doing it herself (going on vacation).

Clas' response in line 15 constitutes a third position repair (Schegloff 1992), in which he dismisses her response as inappropriate and specifies what he meant to ask ("I'm only asking..."). His reference to the fact that he himself is also going on vacation challenges the legitimacy of her account, and the contrastive stress on "political" indicates that her reason cannot be considered as such a reason. It is not made explicit what is meant by "political reason", but Mats displays his understanding of it by providing one, namely "going to a higher level" (line 22). This is an instance of what we have referred to above as a formulation of strategy, presented in an assessment format ("it's a good thing..."), thus invoking its beneficial effect for the operation of the company. Also Vesa provides such a motivation by stressing the increased impact of a call from the editor ("not calling for fun", line 26). Even before Vesa has made his point, both Clas and Liisa seem to accept Mats's reason as settling the question. Clas produces a positive response token (line 24) and Liisa starts making practical arrangements by giving him a piece of paper with the telephone number (line 29). Clas sums up and closes the topic by a formulation of upshot in which he explicitly commits himself to the task (line 44).

This excerpt does not contain a request, but rather the acceptance of an offer. However, it still involves negotiation about (re-)assigning a task to an individual and what counts as a legitimate reason for doing so. It is especially interesting to the topic under discussion here, since the manager explicitly comments on what are to be considered legitimate and non-legitimate reasons for reassigning the task to him. $\mathrm{He}$ dismisses the account presented by Liisa, which invokes benefits to her as a private person and instead favors Mats's account, which is framed as a formulation of strategy and highlights the beneficial effect for the organization.

In the next excerpt we can observe another conflict between the members of the editorial board on what are the legitimate grounds for assigning a task to one of the participants. In addition to the participants who were active in the excerpt above, 
we also have the secretary Gudrun $(G)$ and the journalist Karl $(K)$, who is standing by the white board taking notes for the publication plan. The excerpt starts as the editor introduces a new topic, a column called 'Inventing people', and goes on to assign space for each country involved:

(6) Inventing people

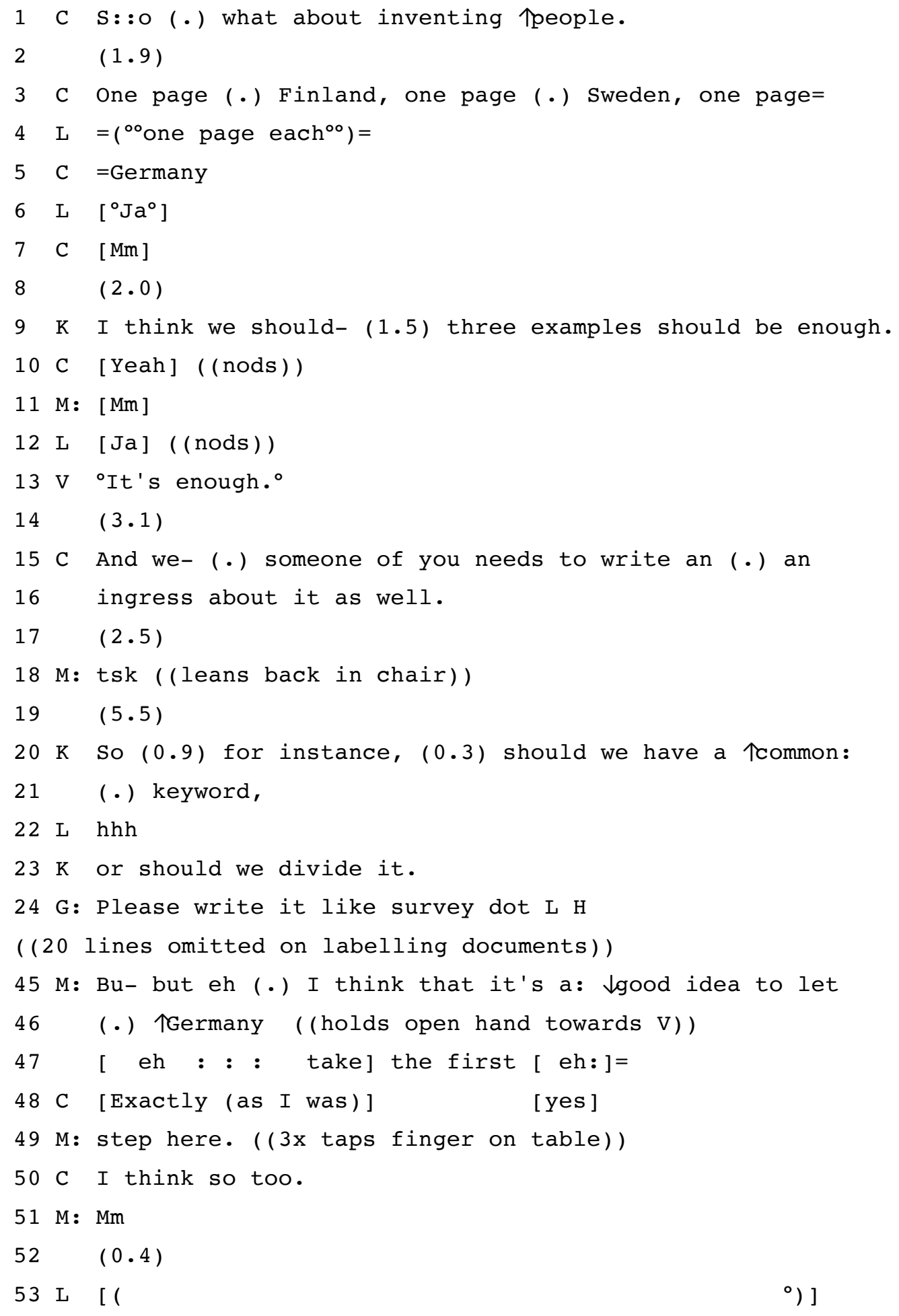




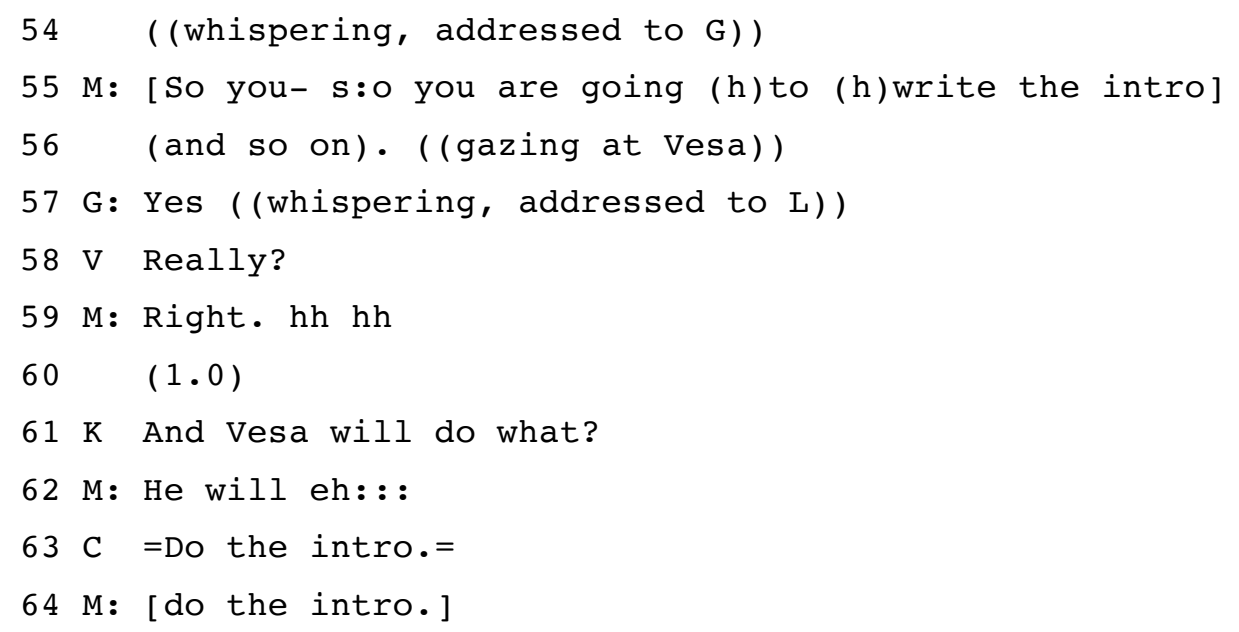

The editor, Clas, opens the topic by laying out a plan for devoting one page to each of the countries involved. Since the participants have responsibility for different countries, this may implicitly involve assigning tasks to the different participants. In addition, he mentions another responsibility, writing a common introduction ("ingress") to the column (line 15). In doing so, he performs a self-repair, replacing "we" by "someone of you". This changes the status of the utterance from a mere statement of need to a request for action. Furthermore, it points to the relevance of chosing one of the three rather than just leaving it as a collective responsibility.

After a side sequence, in which the secretary instructs them how to label their documents (omitted), Mats resumes the sequence initiated by Clas by proposing to "let Germany take the first step” (line 45). The reference to 'Germany' exploits their common knowledge of who is responsible for that country, namely Vesa (cf. Markaki \& Mondada 2012). The proposal is presented as "a good idea", whereby Mats accounts for the suggestion by reference to its potentially beneficial effects. Furthermore, by using the deontic verb of permission 'let', he implies that Germany has a wish to do it and the role of the others is to merely to allow or refuse it. This constitutes a rather common manipulation of the benefactive gradient, presenting a request as an offer (cf. Clayman \& Heritage, 2014). Clas immediately joins in with an emphatic agreement ("exactly", line 48). He thereby aligns as a team with Mats 
(Djordjilovic, 2012b), and this alliance, especially given his status as editor, adds deontic force to the suggestion.

As the suggestion indirectly constitutes a request to Vesa, it also makes a response from him the next relevant action. But no response is forthcoming, and Mats then turns to Vesa and addresses him explicitly by the pronoun 'you' (line 55). ${ }^{3}$ His utterance is not formatted as a request, but rather an announcement of a decision, thus treating Clas' response as having settled the case without Vesa having responded. This utterance is hearable as joking, not just by the interspersed laughter, but also in that the announcement constitutes a seemingly exaggerated display of authority (taking a decision over Vesa's head) and in that he expresses a deontic stance (of definite authority) that is not in line with his deontic status (as a peer of Vesa and not his manager). Vesa responds to this with the news marker"'really?" (line 58), thereby taking up the joking tone and treating it as a mere announcement. Simultaneously, the literal meaning of this news marker is an indication of incredulity, and thus it may be heard as questioning the truth or the legitimacy of the statement (and thereby also it's deontic implications). Mats follows up this humoristic framing by merely confirming ("right") and laughing.

The question of who should write the intro might have been settled at this point, but as we shall see, the humorous frame is used as an occasion for Vesa to 'get back at' Mats. The next excerpt follows directly from the previous:

(7) Inventing people (ctd.)

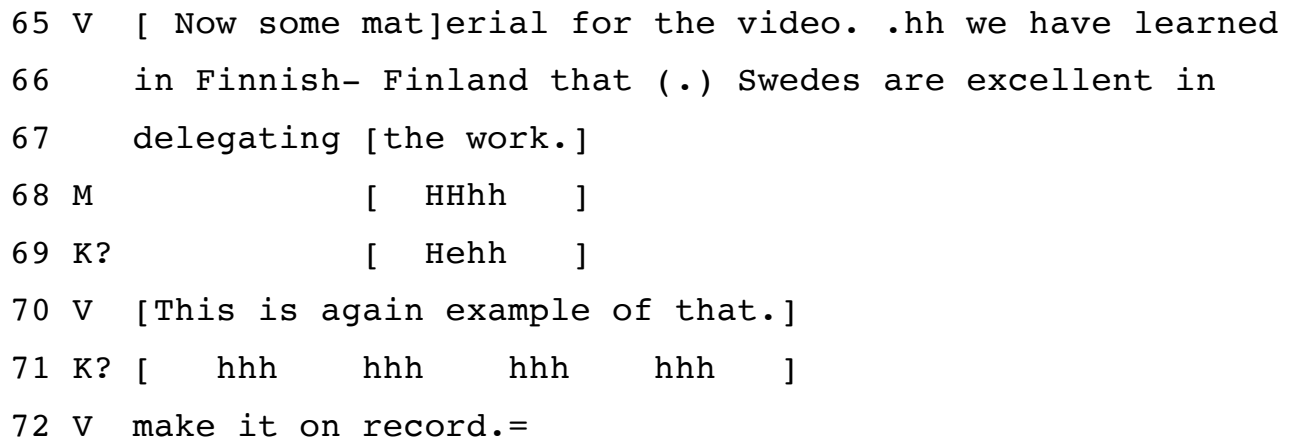

3 Simultaneously, Liisa addresses an inaudible utterance to Gudrun (line 54-55) and Gudrun answers (line 57). Their low voice and mutual gaze constitute this as a private aside. 


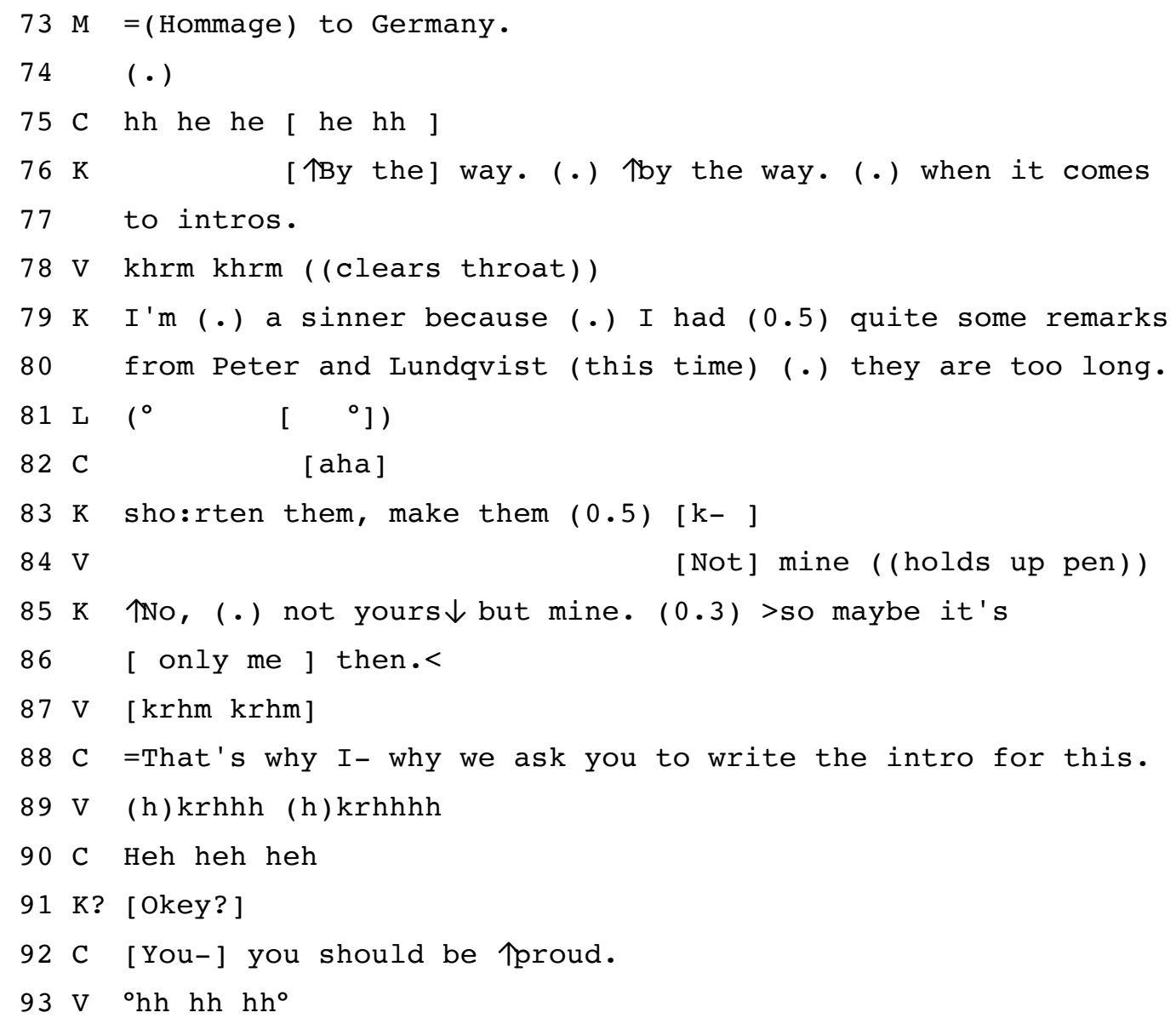

At this point, Vesa makes a metacommunicative statement about this episode, framed as "material for the video" (I. 65-67) (i.e. the researchers), in which he presents it as an example of a Swedish national trait, namely being good at delegating work. In this environment, this is hearable not as a compliment, but rather as a (joking) accusation of Swedes (and by implication, Mats) eschewing work themselves. A common response to banter is to produce a 'return', that is, a playful counter. Even before he completes his turn, two of the participants (M and $\mathrm{K}$ ) start laughing and thus display their understanding of it as humorous. And the manager, Clas, joins in. Mats's response "Hommage to Germany" (line 73) may be heard as a retrospective specification of his own utterance in line 45-49 (about "letting Germany take the first step"). He thereby dismisses Vesa's interpretation (as eschewing the job himself) and offers instead an alternative understanding of it as a gesture of honor to Vesa, thus again presenting him as the beneficiary of an offer rather than the agent 
of a requested action. Clas, who had aligned with Mats in making the initial request, supports Mats by laughing at his joke (line 75).

Karl shifts the topic by a misplacement marker ("by the way", line 76) and starts talking about shortening their "intros". Vesa's unmitigated misalignment in line 84 ("not mine") might be carrying on the playful and bantering tone from before (given the blunt self-praise involved), but it is not treated as such by Karl, who instead backs down and takes the blame on himself ("so maybe it's only me then" lines 85-86). But Clas seems to hear Vesa's utterance as playful in that he reopens the banter and claims that this is the reason Vesa is asked to write the intro (note the self-repair from "I" to "we", thus realigning with Mats). The humorous character is confirmed by Vesa starting laughing (although in the midst of coughing, line 89), and Clas following up the laughter. In adding that Vesa "should be proud" (line 92), Clas continues to account for the request as a reward to Vesa rather than a burden placed on him. However, he may also be heard as implying a more institutionally legitimate reason, namely that the best person is chosen for the job.

In this excerpt we can observe a playful disagreement about the legitimate reasons for assigning a task. Mats repeatedly presents the request as an offer to Vesa, thereby inversing the benefactive gradient from an imposition to a favor. Vesa counters this move by claiming that Mats does this for his own benefit, thus invoking an illegitimate, personal motivation for the request. Finally, Clas, their manager, provides yet another (and more serious) account for the request by motivating it in the benefits for the organization. All in all, by breaching the norms of task assignment and joking about the reasons for doing so, the participants bring the norms to the surface, namely that requests for action should be grounded in beneficial effects for the organization (the best man for the job) and not in personal benefits (eschewing the task oneself). 


\section{Conclusion}

When members of organizations propose to assign a task to colleagues they may treat their action as in need of an account. In our material, accounts are given when tasks are not treated as a part of the organizational routine, when the responsibility for the task is disputable, or when the participant's rigt to assign the task can be questioned. . The accounts analyzed here generally invoke the benefits of the proposed action for the successful operation of the company. Although they may sometimes be formulated as benefitting individuals or groups in the company (such as the IT-managers in (4)), it is in their capacity as employees carrying out their work responsibilities and not in their capacity as private individuals. In the deviant cases where such personal reasons were indeed provided as accounts, they were either presented as non-serious (such as eschewing work in (6)) or they were dismissed as inappropriate (going on summer vacation in (5)). Thus benefactive effect to the organization seems to be the main resource for legitimizing requests for future action in this context. This confirms the claim made by Clayman \& Heritage (2014) that benefactive stance is a central resource in accounts for requests. However, in our organizational data, it is not the speaker who is presented as the main beneficiary, but the organization. This pattern of accounting practices seems to indicate that the organizational members see themselves as having a joint commitment to a shared project (cf. Rossi 2012) and use this as the main grounds for legitimizing assigning task to others. The successful operation of the company thus represents an important shared premise for warranting institutionally relevant actions.

An important resource used in the accounts we have studied is formulating general strategies or guidelines for the operations. These 'policy statements' constitute more general or abstract principles or norms for action at various organizational levels. They may be formulated with strong deontic stance, claiming necessity ('we have to have one voice' (4)), or they may display a weaker stance, merely claiming desirability of the action ('it's a good idea to...' (5)). The action of 
'formulating policy' is usually associated with managers, but we have seen that also subordinates may use such formulations to account for their requests. It may be considered a method for strengthening the speaker's deontic stance, given that it grounds the request in socially legitimate interests outside the personal concerns of the speaker. Implicitly, 'policy statements' are also built on epictemic grounds, because they rely on the participants' shared values and shared knowledge about how their organization functions. In our data, organizational strategies provide grounds for the legitimate motivations, but a topic for further research could be to investigate whether other types of policy statements are used to account for requests in other types of settings.

Finally, we have shown that the participants orient to their varying deontic statuses in several ways. The manager's institutional authority is manifested by the fact that he uses rather few accounts in backing his task assignment and in that his entitlement to assign the task is taken for granted in the subordinates' response. Subordinates, by contrast, use extensive accounts to legitimate their requests to their manager or their peers. We have also seen that subordinates' requests are vulnerable to being challenged or questioned, thus reflecting (and co-constructing) their weak institutional authority. We can thus conclude that deontic status is relevant for how requests are formulated and accounted for in meeting interaction. This complements and substantiates previous findings on the primacy of deontic status over stance (cf. Heritage 2012, Peräkylä \& Stevanovic 2014). It further contributes to specifying how institutional roles and relations are reflected and constructed in interaction. Although we find our examples in meetings, we do not expect that the patterns observed are specific to this activity type, but this would also need empirical substantiation in another study. 
References

Antaki, Charles, 1994. Explaining and Arguing. The Social Organization of Accounts. Sage Publications, London.

Barnes, Rebecca, 2007. Formulations and the facilitation of common agreement in meetings talk. Text \& Talk 27, 273-296.

Clayman, Steven \& Heritage, John, 2014. Benefactors and beneficiaries: Benefactive status and stance in the management of offers and requests. In: Drew, P. \& Couper-Kuhlen, E. (Eds.), Requesting in Social Interaction. Amsterdam: John Benjamins, pp. 51-82.

Djordjilovic, Olga, 2012a. 'Being strategic' and 'being practical': Displaying deontic rights in management meeting interaction. In: Djordjilovic, Olga, Managing tasks and Relations in Meeting Interaction. PhD dissertation, University of Oslo, pp 87-121.

Djordjilovic, Olga, 2012b. Displaying and developing team identity in workplace meetings - a multimodal perspective. Discourse Studies 14, 111-127.

Ford, Cecilia. E., 2008. Women Speaking up. Getting and Using Turns in Workplace Meetings. New York, Palgrave.

Garfinkel, Harold, 1967. Studies in Ethnomethodology. Polity Press, Cambridge, UK. Heritage, John, 1984. Garfinkel and Ethnomethodology. Polity Press, Cambridge, UK.

Heritage, John, 2012. Epistemics in action: Action formation and territories of knowledge. Research on language and social interaction 45(1), 1-29.

Kangasharju, Helena, 2007. Interaktion och inflytande. Finländare och svenskar vid mötesbordet [Interaction and influence. Finns and Swedes meet at the meeting table]. In Kangas, O. \& Kangasharju, H. (Eds.), Ordens Makt och Maktens Ord [The power of words and the words of power]. Svenska Litteratursällskapet $\mathrm{i}$ Finland, Helsinki, pp 341-377.

Markaki, Vassiliki \& Mondada, Lorenza, 2012. Embodied orientations towards coparticipants in multinational meetings. Discourse Studies 14, 31-52.

Rossi, Giovanni, 2012. Bilateral and unilateral requests: The use of imperatives and Mi X? interrogatives in Italian. Discourse Processes, 49(5), 426-458.

Sacks, Harvey, 1987. On the preferences for agreement and contiguity in sequences in conversation. In: Button, G. \& Lee, J.R. (Eds.), Talk and Social Organisation. Multilingual Matters, Clevedon, pp. 54-69

Sacks, Harvey, 1992. Lectures on Conversation. Blackwell Publishing, Oxford, UK. 
Schegloff, Emanuel A., 1992. Repair after next turn: The last structurally provided defense of intersubjectivity in conversation. American Journal of Sociology 97, 1295-1345

Stevanovic, Melisa, 2011. Participants' deontic rights and action formation: The case of declarative requests for action. Interaction and Linguistic Structures (InLiSt) 52. , URL: http://www.inlist.uni-bayreuth.de/issues/52/InLiSt52.pdf (accessed 1.10.2014)

Stevanovic, Melisa \& Peräkylä, Anssi, 2012. Deontic authority in interaction: The right to announce, propose, and decide. Research on Language \& Social Interaction 45, 297-321.

Stevanovic, Melisa \& Peräkylä, Anssi, 2014. Three orders in the organization of human action: On the interface between knowledge, power, and emotion in interaction. Language in Society 43, 185-207

Stevanovic, Melisa \& Svennevig, Jan (this issue). Introduction: Epistemics and deontics in conversational directives.

Stivers, Tanya, 2011. Morality and question design: "of course" as contesting a presupposition of askability. In: Mondada, L. and Steensig, J. (Eds.), Morality of Knowledge in Conversation. Cambridge University Press, Cambridge, pp. 82106.

Svennevig, Jan 2011. Leadership style in managers' feedback in meetings. In: Angouri, J \& Marra, M. (Eds.), Constructing Identities at Work. Palgrave, London, pp. 17-39.

Svennevig, Jan, 2012a. Introduction: Interaction in workplace meetings. Discourse Studies 14, 3-10.

Svennevig, Jan, 2012b: The agenda as resource for topic introduction in workplace meetings. Discourse Studies 14, 53-66.

Vine, Bernadette, 2004. Getting Things Done at Work. The Discourse of Power in Workplace Interaction. John Benjamins, Amsterdam. 